\title{
Sulfoquinovosyl oleoyl palmitoyl glycerol (SQDG) and hexane extract of Sargassum plagyophylum prevent depression induced by dexamethasone or stress in mice
}

\author{
Afsaneh Yegdaneh $^{1}{ }^{\circledR}$, Azadeh Mesripour $^{2^{*}}{ }^{\circledR}$ Marjan Keyvani $^{2}{ }^{\circledR}$ \\ ${ }^{1}$ Department of Pharmacognosy, School of Pharmacy and Pharmaceutical Sciences, Isfahan University of Medical Sciences, Isfahan, Iran \\ ${ }^{2}$ Department of Pharmacology and Toxicology, School of Pharmacy and Pharmaceutical Sciences, Isfahan University of Medical Sciences, Isfahan, Iran
}

\section{A R T I C L E I N F O}

Article Type:

Original Article

Article History:

Received: 10 August 2020

Accepted: 7 December 2020

Keywords:

Sargassum plagyophylum

Sulfoquinovosyl diglyceride

Depression

Stress

Dexamethasone

\begin{abstract}
A B S T R A C T
Introduction: M Glucocorticoids and stress are a leading cause of depression by dysregulation of hypothalamic hypophyseal adrenal axis. Sargassum plagyophylum hexane extract (HxE) has proven antidepressant-like effects in mice. We aimed at evaluating $\mathrm{HxE}$ and sulfoquinovosyl oleoyl palmitoyl glycerol (SQDG) isolated compound antidepressant effects following dexamethasone (Dex) or water avoidance stress (WAS) induced depression in mice.

Methods: The HxE was prepared and fractionated by different chromatography methods to isolate active compounds. Depression was induced in male mice by Dex single dose or by four days of WAS. After the locomotor test, depression was assessed by measuring the immobility time during the forced swimming test (FST) and sucrose preference test.

Results: 6-Deoxy-6-sulpho- $\alpha$-D-glucopyranosyl-1,2-O-diacyl-glycerol was isolated and elucidated from the seaweed. The manipulations did not cause important changes in animals' locomotor activity. During FST, immobility time increased dramatically by Dex $(193 \pm 13 \mathrm{~s}$ vs control $109 \pm 7 \mathrm{~s}$ ) or WAS ( $189 \pm 13 \mathrm{~s}$ vs sham $86 \pm 14 \mathrm{~s})$, that indicated depression. HxE 40 $\mathrm{mg} / \mathrm{kg}$ reduced the immobility time when it was administered with Dex $(110 \pm 28 \mathrm{~s}, P<0.01$ vs Dex alone) or together with WAS ( $86 \pm 11 \mathrm{~s}, P<0.001$ vs WAS). SQDG $40 \mathrm{mg} / \mathrm{kg}$ reduced the immobility time when co-administered with Dex ( $22 \pm 9 \mathrm{~s}, P<0.001$ vs Dex alone) and when it was administered along with WAS ( $68 \pm 16 \mathrm{~s}, P<0.001$ vs WAS). The results of the sucrose preference test were in line with FST results as sucrose preference below $65 \%$ was considered for anhedonia.

Conclusion: SQDG and probably the steroid content in S. plagyophylum HxE prevented depression in mice; thus, they should be considered for further clinical evaluations.
\end{abstract}

Implication for health policy/practice/research/medical education:

Sargassum plagyophylum hexane extract $(\mathrm{HxE})$ and sulfoquinovosyl oleoyl palmitoyl glycerol (SQDG) isolated compound showed antidepressant effects following dexamethasone or water stress induced depression in mice. Therefore they could be promising alternative medicine for preventing depression in high risk individuals, namely patients under glucocorticoid therapy or under stressful conditions.

Please cite this paper as: Yegdaneh A, Mesripour A, Keyvani M. Sulfoquinovosyl oleoyl palmitoyl glycerol (SQDG) and hexane extract of Sargassum plagyophylum prevent depression induced by dexamethasone or stress in mice. J Herbmed Pharmacol. 2021;10(2):262-268. doi: 10.34172/jhp.2021.30.

\section{Introduction}

Stressful events in life have an important association with major depression disorder (MDD) (1). Malfunctioning of the hypophysis hypothalamic adrenal axis (HPA) has been observed in many depressed individuals (2). The link between cortisol and depressive symptoms is further drawn by the observation that patients with elevated glucocorticoid (GC) levels, such as Cushing's syndrome or synthetic GC therapy, induce psychiatric symptoms similar to those observed in $\operatorname{MDD}(3,4)$. Apart from the cardiovascular effects of GCs, a growing amount of literature reporting on animal studies indicate 
that administration of high doses of stress hormone corticosterone (analog to cortisol in humans), or synthetic GC (such as dexamethasone) causes a depressive-like behavior in rodents $(5,6)$.

The major clinical drawbacks of antidepressant drugs are the heterogeneity of the clinical responses and susceptibility to adverse effects. There has been attention to the medicinal plants for different purposes because of the wide variety of natural products (7). Therefore, there has been more attention to alternative therapy for depression such as vitamins and herbal medicine $(7,8)$. Some marine macro-algae plants have demonstrated the potential to be a good source of new drugs for neurological disorders therapy $(9,10)$. Previously, the different extracts of Sargassum ilicifolium; hexane extract (HxE) of S. plagyophylum have proven antidepressant-like effects in mice $(11,12)$. Anionic glycoglycerolipids such as sulfoquinovosyl oleoyl palmitoyl glycerol (SQDG) is one of the most saturated glycoglycerolipids contents in all photosynthetic plants and algae $(13,14)$. Evidently, natural and synthetic forms of glycoglycerolip ${ }^{\circ}$ ids have important biological functions such as anti-tumor, anti-inflammatory, and immunosuppressive effects (14-16). Therefore, isolation and bioactivity analysis of glycoglycerolipid molecules is an interesting area in the field of marine chemistry. Sulfoquinovosyl oleoyl palmitoyl glycerol is one of the SQDG substances isolated from the seaweed S. plagyophylum, which was evaluated here on two depression models for the first time.

Sargassum belongs to a large genus of brown seaweeds consisting of over150 species, such as S. plagyophylum, found in the Persian Golf of Iran. Recent researches have shown that there are more than 150 species of marine algae in the coastal area of Iran (15). Nevertheless, there have been only a few studies regarding the effects of the marine algae in this region, especially Sargassum species, on depression. Hence, it is necessary to conduct a comprehensive study on anti-depression activities of these marine algae and their metabolites. In the following research in order to widen our knowledge regarding the potential antidepressant effects of S. plagyophylum: the antidepressant effects of HxE and SQDG were evaluated in dexamethasone (Dex) treated mice. In addition, their effectiveness was also analyzed following animal exposure to stress.

\section{Material and Methods}

Authentication of plant material

The seaweeds were collected from the Persian Gulf coasts of Iran on the outskirts of Bushehr Province. Bushehr Agricultural and Natural Resources Research Center recognized them and designated voucher variety code number 2662 and were finally stored in the herbarium of the School of Pharmacy and Pharmaceutical Sciences of Isfahan University of Medical Sciences (Iran).
Preparation of the extracts

At room temperature, the powder obtained from $S$. plagyophylum was extracted with ethyl acetate/methanol 1:1 (v/v). The extract was filtered and dried and then partitioned into hexane and methanol. The $\mathrm{HxE}$ was used for the further anti-depression test.

\section{Preparation of SQDG}

Hexane partition was additionally fractionated by medium pressure liquid chromatography. A gradient solvent system from $100 \%$ hexane to $100 \%$ EtOAc was used on a silica gel column. All elutions were screened by thin-layer chromatography and proton nuclear magnetic resonance (1H-NMR) and divided into 14 fractions (Frs. 1-14). Fraction F14 was additionally purified on another column with chloroform/methanol and increasing concentrations of methanol $(95: 5,90: 10,80: 20,50: 50 \mathrm{v} / \mathrm{v})$ in the end to $100 \%$ methanol. The eluates were combined in 12 ending fractions. Fractions F14i were further isolated by highperformance liquid chromatography (HPLC) separation yielded the pure compound.

Animals

Male albino mice (weighing $25 \pm 2$ g, 6-8 weeks old) were nurtured at room temperature $\left(21 \pm 2^{\circ} \mathrm{C}\right)$ with free access to standard mice chow and tap-water, on a 12-hour light and 12-hour dark cycle (lights on at 6 AM). Totally, 15 groups of animals consisting 6 mice in each group were studied. In each cage, six mice were kept together, that was placed in the behavioral laboratory 24 hours prior the experiments in order to acclimate. The behavioral tests were conducted in the morning until 2 pM. The experiments were carried out according to the guidelines for the Care and Use of Laboratory Animals Issued by The National Ethical Committee of Iran (Ethical No: IR.MUI. RESEARCH.REC.1399.171). All the attempts were made in the research to reduce animal agony and the number of animals used in the research.

\section{Water avoidance stress (WAS)}

The test was performed in a plexiglas container that was filled with shallow water $\left(22^{\circ} \mathrm{C}\right)$ within $1 \mathrm{~cm}$ of the top of a platform attached in the center. In four consecutive days, each mouse was placed on the platform daily for 1 hour duration. The sham group included animals that were placed in the waterless container.

\section{Therapies}

A single dose of Dex $(8 \mathrm{mg} / 2 \mathrm{~mL}$ ampule, Raha Industry, Iran; $250 \mathrm{mcg} / \mathrm{kg}$ ) was injected SC three hours before the tests, while control animals received normal saline (6). S. plagyophylum $\mathrm{HxE}$ (20 and $40 \mathrm{mg} / \mathrm{kg}$ ) (referred to as HxE20, HxE40) was administered IP (diluted in $0.1 \%$ tween 80; Merck, Germany). SQDG (20 and $40 \mathrm{mg} / \mathrm{kg}$ ) (referred to as SQDG20, SQDG40) was administered IP 
(diluted in normal saline). As a reference antidepressant, the selective serotonin reuptake inhibitors (SSRI) drug fluoxetine $\mathrm{HCl}$ (a gift from Pars Daru, Iran) $20 \mathrm{mg} / \mathrm{kg}$ was injected IP half an hour before the tests. The volume adjusted for all of the injections was $10 \mathrm{ml} / \mathrm{kg}$ mice body weight.

Experiments were continued with HxE40 or SQDG40 that showed antidepressant-like effects. They were coadministration with Dex and tested after three hours. Furthermore, in separate groups HxE40 and SQDG40 were administered each day following WAS, and the behavior tests were performed on the fifth day.

\section{Locomotor test}

This test is performed prior to psychopharmacological tests in order to confirm normal locomotor behavior. The locomotor test was performed in an open arena (Borj Sanat, Iran) that was divided into fifteen equal zones by red beams. Mice were carefully put in the corner of the apparatus free to explore it for 3 minutes duration. By crossing the beams, the number of zone entries was counted automatically, and the rears on hind-legs were recorded manually. Ultimately, the total activity counted for each animal was calculated by summing-up zone entries and rears.

\section{Forced swimming test (FST)}

This test evaluates mice despair behavior by measuring the immobility time; it was performed after the locomotor test. Each mouse was placed in a 2-L PYREX beaker (93 $\mathrm{mm}$ depth and131 $\mathrm{mm}$ in diameter), filled with water $\left(25^{\circ} \mathrm{C}\right)$, and forced to swim for $6 \mathrm{~min}$. Different behaviors were measured during the last 4 minutes of the trial after 2 minutes of habituation. Behaviors included the immobility time characterized when the mouse had no additional activity except for that required to keep its head out of water; climbing time defined when the animal tried to climb up the cylinder wall and swim (17). A camera mounted above the beaker recorded the experiments, and were analyzed later. Finally, animals were dried carefully to avoid hypothermia and placed back in their home cage.

\section{Sucrose preference test}

This test measured anhedonia in mice; it was performed in three days. The first two days were for habituation; on the first day two bottles of sucrose solution (5\% w/v), and on the second day two bottles were applied in the animals' home cage. One contained sucrose solution and the other water. On the third day, two bottles were placed in each cage that contained $100 \mathrm{~mL}$ of sucrose solution or tap water. After 24 hours, by measuring the amount of water or sucrose solution that was utilized the percentage for sucrose preference was calculated. Sucrose preference percentage was measured the day after the behavior tests ended.
Data processing and statistical analysis

Data statistical evaluation was performed by using Excel 2010 and the GraphPad Prism 6 software (La Jolla, CA, USA). Behavioral results for each group were presented as mean \pm SEM, analyzed by one-way analysis of variance (ANOVA) and Tukey's multiple comparison tests. Values of $P<0.05$ were defined as statistically significant.

\section{Results}

Structure elucidation of the isolated compound

Analyzing different types of NMR data, including 1H-NMR, CNMR, 1H-1H COSY, DEPT, HSQC, and ${ }^{1} \mathrm{H}_{-}{ }^{13} \mathrm{C}$ heteronuclear multiple bond correlation spectroscopy (HMBC), authorized issuing of isolated compound. Regarding a glycerol moiety $(\delta \mathrm{H} 4.32$ and 4.12

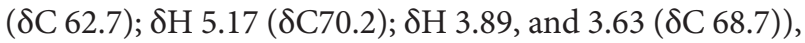
one spin systems were distinguished.

HMBC $(\delta \mathrm{H} / \delta \mathrm{C}: 5.17$ (Hsn-2)/174.5, 175(COO); 4.32 and 4.12 (Hsn-1)/172.4, 172.6 (COO); 2.28 ( $\alpha-\mathrm{CH} 2) /$ $172.4,172.6$ (COO)) showed acyl groups on the sn-1 and sn-2 positions of the glycerol moiety. Therefore, the signals of second spin were in correlation with two terminal methyl signals of fatty acyl overlapped at $\delta \mathrm{H} 0.84$ $(6 \mathrm{H}, \mathrm{t}, \mathrm{J}=6.8 \mathrm{~Hz}, \delta \mathrm{C} 14.5)$.

The $a$ orientation of the glycoside group was resulted from the relative small coupling constant value of the anomeric proton $\left(\mathrm{H}-1^{\prime \prime \prime}\right), \mathrm{J}=3.5 \mathrm{~Hz}$, while the huge proximate coupling constants between $\mathrm{H}-2$ ' ' $/ \mathrm{H}-3$ '"',

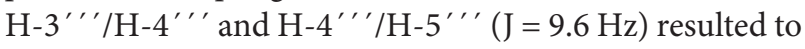
the glucopyranosyl nature of the sugar union.

Besides, the existence of a sulphonyl group attach at C- 6 " ' carbon of the sugar moiety was elucidated from the characteristic chemical shifts of the methylene protons in both.

All data from $1 \mathrm{H}$ - and 13C-NMR spectra are representing the existence of 6-deoxy-6-sulpho- $\alpha-\mathrm{D}$ glucopyranosyl-1,2-O-diacyl-glycerols. For identification of the acyl substituents at sn- 1 and sn-2, alkaline hydrolysis was also done. The isolated compound was exposed to alkaline hydrolysis with sodium methoxide in methanol and resulted in oleoyl and palmitoyl fatty acids (16).

The effect of HxE following Dex injection or WAS As it is shown in Table 1, the selected doses of treatments and WAS did not induce a noticeable change in the animals' locomotor activity. During the FST in animals treated with HxE40 the immobility time was significantly lower ( $31 \pm 5 \mathrm{~s}$ vs. vehicle $148 \pm 20 \mathrm{~s}, P<0.001)$ that clearly indicated the anti-depressant like effect (Figure 1A). By injecting Dex or imposing the animals to WAS, immobility time increased dramatically $(193 \pm 13 \mathrm{~s}$ vs. control $109 \pm 7$ and $189 \pm 13$ s vs. sham $86 \pm 14$ s, $P<0.01$; respectively), indicating depression-like behavior. HxE40, similar to Flx, clearly reduced the immobility time when it was administered with Dex $(110 \pm 28 \mathrm{~s}, P<0.01$ vs. Dex alone $)$ or together with WAS $(86 \pm 11 \mathrm{~s}, P<0.001$ vs. WAS $)$. The 
Table 1. The effect of Sargassum plagyophylum hexane extract on total activity during locomotor test and activities during forced swimming test

\begin{tabular}{|c|c|c|c|c|c|c|c|}
\hline \multirow[b]{2}{*}{$\begin{array}{l}\text { Group } \\
(n=6)\end{array}$} & \multirow[b]{2}{*}{$\begin{array}{l}\text { Locomotor total } \\
\text { activity (count) }\end{array}$} & \multicolumn{2}{|c|}{ FST } & \multirow[b]{2}{*}{$\begin{array}{l}\text { Group } \\
(n=6)\end{array}$} & \multirow{2}{*}{$\begin{array}{l}\text { Locomotor } \\
\text { total activity } \\
\text { (count) }\end{array}$} & \multicolumn{2}{|c|}{ FST } \\
\hline & & $\begin{array}{l}\text { Swimming } \\
\text { time (s) }\end{array}$ & $\begin{array}{l}\text { Climbing } \\
\text { time (s) }\end{array}$ & & & $\begin{array}{l}\text { Swimming } \\
\text { time (s) }\end{array}$ & $\begin{array}{c}\text { Climbing } \\
\text { time (s) }\end{array}$ \\
\hline Vehicle & $147 \pm 19$ & $62 \pm 12$ & $31 \pm 8$ & Dex+ HxE40 mg/kg & $194 \pm 19$ & $87 \pm 16^{\mathrm{dd}}$ & $43 \pm 13$ \\
\hline HxE20 mg/kg & $187 \pm 17$ & $49 \pm 19$ & $89 \pm 13^{\wedge}$ & Dex+ Flx & $130 \pm 21$ & $143 \pm 9^{\text {ddd }}$ & $91 \pm 7^{* \text { ddd }}$ \\
\hline $\mathrm{HxE} 40 \mathrm{mg} / \mathrm{kg}$ & $141 \pm 12$ & $87 \pm 12$ & $125 \pm 18^{\wedge \wedge \wedge}$ & Sham & $187 \pm 21$ & $98 \pm 15$ & $39 \pm 8$ \\
\hline Control & $131 \pm 21$ & $85 \pm 18$ & $58 \pm 4$ & WAS & $167 \pm 13$ & $32 \pm 8^{* *}$ & $23 \pm 8$ \\
\hline Dex & $176 \pm 12$ & $30 \pm 7 *$ & $23 \pm 6^{* *}$ & WAS+ HxE40 mg/kg & $119 \pm 19$ & $114 \pm 6^{\mathrm{SS}}$ & $41 \pm 12$ \\
\hline
\end{tabular}

FST, Forced swimming test; HxE, Hexane extract; Dex, dexamethasone; WAS, water avoidance stress.

Total activity = horizontal + vertical counts. The results presented as mean \pm SEM, were evaluated by ANOVA and completed by Tukey's comparison tests.

$\wedge P<0.05, \wedge \wedge \wedge P<0.001$ vs. vehicle; ${ }^{*} P<0.05, * * P<0.01, * * * P<0.001$ vs. control; ${ }^{*} P<0.01,{ }^{\text {ddd }} P<0.001$ vs. Dex group; ${ }^{\text {ss }} P<0.01$ vs. WAS group.

sucrose preference test shown in Table 2 also supports the FST results as a decline in sucrose preference below $65 \%$ was considered an aspect of anhedonia. As shown in Table 1 , although the climbing was the main activity during the FST following HxE administration, the co-administration of HxE40 with Dex or WAS caused noticeable changes in the swimming time compared with Dex or WAS alone that was similar to Flx.

The effect of SQDG following Dex injection or WAS According to Table 3, administrating the selected SQDG doses did not change the locomotor activity. Figure 1B shows that SQDG40 has caused a noticeable decline in the immobility time during FST showing its antidepressantlike effect, which was further supported by the sucrose preference test (Table 2). SQDG40 significantly decreased the immobility time during FST when co-administered with Dex $(22 \pm 9 \mathrm{~s}, P<0.001$ vs Dex alone $)$ and when it was administered with WAS exposure $(68 \pm 16 \mathrm{~s}, P<0.001$ vs. WAS alone). The sucrose preference results were parallel with FST results. According to Table 3, SQDG noticeably increased the swimming time that was also high when co-administrated with Dex $(P<0.001$ vs. Dex alone). While administrating SQDG together with WAS mostly increased the climbing time $(P<0.01$ vs. WAS alone).

Table 2. The percentage of sucrose preference in different groups

\begin{tabular}{lccc}
\hline Groups (n=6) & Sucrose preference (\%) & Groups (n=6) & Sucrose preference (\%) \\
\hline Control & 68 & Sham & 67 \\
HxE20 mg/kg & 79 & WAS & 50 \\
HxE40 mg/kg & 80 & Dex+ HxE40 mg/kg & 74 \\
SQDG $20 \mathrm{mg} / \mathrm{kg}$ & 79 & WAS+ HxE40 mg/kg & 72 \\
SQDG40 mg/kg & 77 & Dex+SQDG40 mg/kg & 73 \\
Dex & 55 & WAS+ SQDG $40 \mathrm{mg} / \mathrm{kg}$ & 68 \\
\hline
\end{tabular}

HxE, Hexane extract; SQDG, sulfoquinovosyl oleoyl palmitoyl glycerol; Dex, dexamethasone; WAS, water avoidance stress.

Percentage of sucrose preference $=$ (sucrose utilization/ sucrose + water utilization $) \times 100$. Control and vehicle results were similar; thus, only one was applied.

Table 3. The effect of sulfoquinovosyl oleoyl palmitoyl glycerol (SQDG) on total activity during locomotor test and activities during forced swimming test

\begin{tabular}{|c|c|c|c|c|c|c|c|}
\hline \multirow[b]{2}{*}{$\begin{array}{l}\text { Group } \\
(n=6)\end{array}$} & \multirow[b]{2}{*}{$\begin{array}{l}\text { Locomotor total } \\
\text { activity (count) }\end{array}$} & \multicolumn{2}{|c|}{ FST } & \multirow[b]{2}{*}{ Group $(n=6)$} & \multirow{2}{*}{$\begin{array}{l}\text { Locomotor } \\
\text { total activity } \\
\text { (count) }\end{array}$} & \multicolumn{2}{|c|}{ FST } \\
\hline & & $\begin{array}{l}\text { Swimming } \\
\text { time (s) }\end{array}$ & $\begin{array}{l}\text { Climbing } \\
\text { time (s) }\end{array}$ & & & $\begin{array}{l}\text { Swimming } \\
\text { time (s) }\end{array}$ & $\begin{array}{c}\text { Climbing } \\
\text { time (s) }\end{array}$ \\
\hline Vehicle & $147 \pm 19$ & $62 \pm 12$ & $31 \pm 8$ & Dex+ SQDG40 mg/kg & $147 \pm 27$ & $152 \pm 6 * *$ ddd & $73 \pm 12$ \\
\hline SQDG20 mg/kg & $144 \pm 11$ & $129 \pm 18^{\wedge}$ & $27 \pm 6$ & Sham & $187 \pm 21$ & $98 \pm 15$ & $39 \pm 8$ \\
\hline SQDG40 mg/kg & $146 \pm 18$ & $136 \pm 15^{\wedge}$ & $31 \pm 4$ & WAS & $167 \pm 13$ & $32 \pm 8 * *$ & $23 \pm 8$ \\
\hline Control & $131 \pm 21$ & $85 \pm 18$ & $58 \pm 4$ & & & & \\
\hline Dex & $176 \pm 12$ & $30 \pm 7^{* *}$ & $23 \pm 6 * *$ & WAS+S & $160 \pm 10$ & $68 \pm 13$ & $84 \pm 16^{* 5 s}$ \\
\hline
\end{tabular}

FST, Forced swimming test; Dex, dexamethasone; WAS, water avoidance stress.

Total activity = horizontal + vertical counts. The results presented as mean \pm SEM, were evaluated by ANOVA and completed by Tukey's comparison tests. ${ }^{\wedge} P<0.05$ vs. vehicle; ${ }^{*} P<0.05, * * P<0.01$ vs. control or; ${ }^{\text {ddd }} P<0.001$ vs. Dex group; ${ }^{\text {ss }} P<0.01$ vs WAS group. 

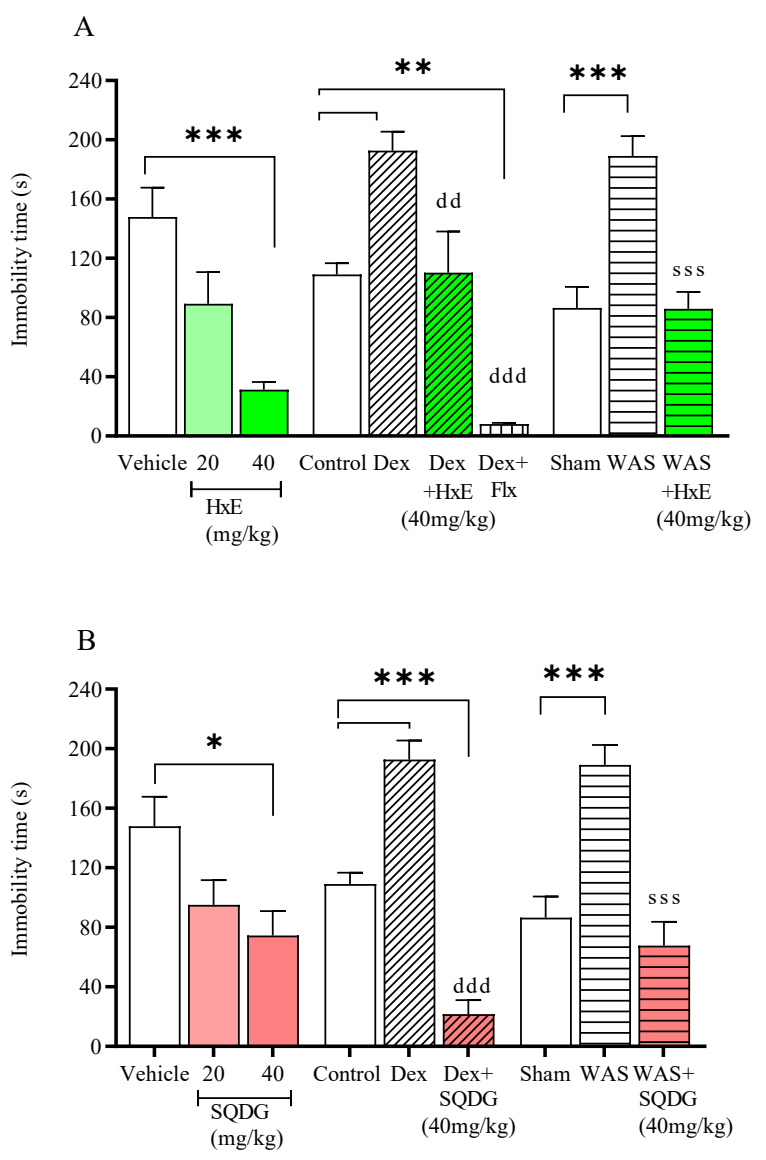

Figure 1. The effect of $S$. plagyophylum hexane extract $(\mathrm{HxE})(\mathrm{A})$ or sulfoquinovosyl oleoyl palmitoyl glycerol (SQDG) (B) on immobility time during forced swimming test (FST). The results were presented as mean \pm SEM, analyzed by ANOVA, and completed by Tukey's comparison tests. ${ }^{*} P<0.05$, ${ }^{* *} P<0.01$, ${ }^{* * *} P<0.001$ vs plain bars; ${ }^{d d} P<0.01$, ddd $P<0.001$ vs, Dex group; sss $P<0.001$ vs WAS group. Dexamethasone (Dex), water avoidance stress (WAS).

\section{Discussion}

These results for the first time proved the potential antidepressant effects of S. plagyophylum HxE and SQDG derivative following mice exposure to Dex or following stress induced depression. Anhedonia is an endophenotype for depression in rodents that was measured by sucrose preference test; the results were parallel with FST despair behavior results (18). In the FST, after placing mice in beaker containing water, the animal slowly loses hope to escape the stressful condition; therefore, the immobility time reflects behavioral despair behavior (18). In addition, measuring climbing time and swimming time during FST could be useful for foreseeing the possible neurotransmitters involved; catecholaminergic related antidepressants commonly show higher climbing time while serotonergic drugs show higher swimming time (17).

WAS is a popular psychological stressor method with outstanding effectiveness to boost adrenocorticotropic hormone and corticosterone within 30 minutes (19). WAS similar to Dex, caused a rise in the immobility time during FST, indicating despair behavior. Indeed anhedonia was assumed since there was no preference of sucrose over water consumption. Previously, it was shown that Dex single administration dose-dependently induce depressive like behavior that was prevented by vitamin B6 (6). Apparently, long term excessive stress induces HPA axis stimulation, resulting in an unusual rise in GCs (20) that leads to mental illnesses, including post-traumatic stress disorder and MDD $(21,22)$. Supporting literature advocate that a GC receptor antagonist, mifepristone initiates a rapid improvement of psychotic depression symptoms in individuals (23). Activation of GC receptor also declines neurotrophins production such as brainderived neurotrophic factor (BDNF) that influence neuronal development and functions (24). Stress and the augmented GC response have negative impacts on the hippocampal neurogenesis (24). On the other hand, GCs also bind to mineralocorticoid receptors (MR) that stimulate neurogenesis. While high dose of Dex attenuated the rat hippocampal progenitor cells growth, a potent $\mathrm{MR}$ agonist (fludrocortisone) showed positive effects and increased cell survival (25). It is suggesting that MR and GC receptor effects on neurogenesis are opposite. The possible involvement of an HPA-axis dysregulation in serotonergic system alterations related to depression has also been reported (26). It could also induce a graded decrease in tyrosine hydroxylase (rate-limiting enzyme of catecholamine biosynthesis) enzyme levels in hippocampal tissues that was parallel with despair behavior in mice (27). These changes induced in neurotransmitters induced by HPA-axis dysregulation following Dex or WAS could be the reason for the observed changes in swimming during FST by administrating the HxE.

In agreement with previous results, $\mathrm{HxE} 40$ showed obvious antidepressant effects (12). While its coadministration with Dex prevented the depressant effects of Dex, similar results were observed when HxE40 was administrated along with WAS. Evidently, some marine macro algae are promising as a novel source of drugs for the treatment of neurological conditions $(10,11)$. The neurological benefits of some natural steroids have been proposed. Steroids produce multiple effects since various effective groups surround a tetracyclic rigid core. These biological signaling molecules accomplish important scientific, chemical, and clinical features (28). Previously, various S. ilicifolium extracts have demonstrated antidepressant-like effects (11). Recently, some steroids such as B-sitosterol purified from $S$. horneri extract have shown antidepressant-like effects in mice during FST and tail suspension test (TST) (10). The antidepressant effects of total sterols were supposedly mediated by an increase in NE and 5-HT in the central nervous system (CNS) (10). Fucosterol extracted from marine algae also demonstrated antidepressant effects in the FST and TST related to similar neurotransmitter 
changes in the CNS, and probably by increasing central BDNF levels (29). Additionally, sargachromenol purified from S. macrocarpum enhanced NGF-dependent neural differentiation and neurite outgrowth from PC12D cells (30). Probably the steroid content of HxE could interrupt with Dex or corticosterone (released following WAS) interaction with steroid receptors that are responsible for neurological changes in depression.

For the first time it was shown that SQDG content of S. plagyophylum had potential antidepressant effects and remarkably prevented Dex and WAS from causing any depressive behavior during FST, and improved anhedonia as observed by the increase in the sucrose preference. Recently another mechanism involved in tricyclic and SSRI antidepressants effectiveness is proposed since they could modulate the transmembrane protein structure attached to the membrane phospholipid bilayer and cause a perturbation in the bilayer energetics contribution (31). Changes in the transmembrane protein structure (thickness, elasticity, and curvature) could also be induced by various amphiphiles, such as many biologically active substances and phytochemicals (32). In addition to GC effect on their nuclear receptors, they have rapid non-nuclear effects that could be related to membrane proteins as well. Therefore, since SQDG is an amphiphilic substance, it may play a role in altering the bilayer cell membrane and membrane protein conformation similar to antidepressant drugs that warrant further evaluation. As SQDG increased swimming time, their effects may resemble the SSRI antidepressants. On the downside of this study, the changes in CNS neurotransmitters were not evaluated, that is recommended for future studies.

To sum up, the steroid content in S. plagyophylum $\mathrm{HxE}$ and SQDG are promising alternative medicine for preventing depression in high-risk individuals, namely patients under GC therapy or under stressful condition that demands additional clinical studies.

\section{Authors' contributions}

AY authenticated and extracted the plant materials, elucidated the structure of the isolated compounds and prepared the manuscript draft; AM conceptualized and designed the research, interpreted the reported study, prepared the manuscript draft and edited it; MK extracted the plant materials and performed pharmacology experiments.

\section{Conflict of interests}

Authors certify that no actual or potential conflict of interest in relation to this article exists.

\section{Ethical considerations}

The protocol was confirmed by the Vice-chancellor in Research Affaires, Medical University of Isfahan (Ethical No: IR.MUI.RESEARCH.REC.1399.171).

\section{Funding/Support}

This work was financially supported through Grant No. 399048 by Isfahan University of Medical Sciences, Isfahan, Iran.

\section{References}

1. Charney DS, Manji HK. Life stress, genes, and depression: multiple pathways lead to increased risk and new opportunities for intervention. Sci STKE. 2004; 2004(225):re5. doi: 10.1126/stke.2252004re5.

2. Naert G, Ixart G, Maurice T, Tapia-Arancibia L, Givalois L. Brain-derived neurotrophic factor and hypothalamic pituitary-adrenal axis adaptation processes in a depressivelike state induced by chronic restraint stress. Mol Cell Neurosci. 2011;46(1):55-66.

3. Anacker C, Zunszain PA, Carvalho LA, Pariante CM. The glucocorticoid receptor: pivot of depression and of antidepressant treatment? Psychoneuroendocrinology. 2011;36(3):415-425.

4. Pivonello R, Simeoli C, De Martino MC, Cozzolino A, De Leo M, Lacuaniello D, et al. Neuropsychiatric disorders in Cushing's syndrome. Front Neurosci. 2015;9:129. doi: 10.3389/fnins.2015.00129.

5. Safaeian L, Ghannadi A, Javanmard SH, Vahidian MH. The effect of hydroalcoholic extract of Ferula foetida stems on blood pressure and oxidative stress in dexamethasoneinduced hypertensive rats. Res Pharm Sci. 2015;10(4):326334.

6. Mesripour A, Alhimma F, Hajhashemi V. The effect of vitamin $\mathrm{B} 6$ on dexamethasone-induced depression in mice model of despair. Nutr Neurosci. 2019;22(10):744-749.

7. Rafieian-Kopaei M. Medicinal plants and the human needs. J Herbmed Pharmacol. 2012;1(1):1-2.

8. Setorki M. Medicinal herbs with anti-depressant effects. J Herbmed Pharmacol. 2020;9(4):309-317.

9. Pangestuti R, Kim SK. Neuroprotective effects of marine algae. Mar Drugs. 2011;9(5):803-818.

10. Zhao D, Zheng L, Qi L, Wang S, Guan L, Xia Y, et al. Structural features and potent antidepressant effects of total sterols and $\beta$-sitosterol extracted from Sargassum horneri. Mar Drugs. 2016;14(7):123. doi: 10.3390/md14070123

11. Yende SR, Harle UN. Antidepressant-like effect of Sargassum ilicifolium in mice model of depression. Adv Pharmacol Toxicol. 2013;14(3):7-13.

12. Mesripour A, Rabiiean N, Yekdane A. The effect of different partitions of seaweed Sargassum plagyophylum on depression behavior in mice model of despair. J Complement Integr Med. 2019;16(4):20180207. doi: 10.1515/jcim-2018-0207. PMID: 31125315.

13. Bruno A, Rossi C, Marcolongo G, Di Lena A, Venzo A, Berrie CP, et al. Selective in vivo anti-inflammatory action of the galactolipid monogalactosyldiacylglycerol. Eur J Pharmacol. 2005;524(1-3):159-168.

14. Matsumoto Y, Sahara H, Fujita T, Shimozawa K, Takenouchi $\mathrm{M}$, Torigoe $\mathrm{T}$, et al. An immunosuppressive effect by synthetic sulfonolipids deduced from sulfonoquinovosyl diacylglycerols of sea urchin. Transplantation. 2002;74(2); 261-267.

15. Akbari V, Zafari S, Yegdaneh A. Anti-tuberculosis and cytotoxic evaluation of the seaweed Sargassum boveanum. 
Res Pharm Sci. 2018;13(1):30-37.

16. Bandyopadhyay SS, Navid MH, Ghosh T, Schnitzler P, Ray B. Structural features and in vitro antiviral activities of sulfated polysaccharides from Sphacelaria indica. Phytochemistry. 2011;72(2-3):276-283.

17. Cryan JF, Page ME, Lucki I. Differential behavioral effects of the antidepressants reboxetine, fluoxetine, and moclobemide in a modified forced swim test following chronic treatment. Psychopharmacology (Berl). 2005; 182(3):335-344.

18. Planchez B, Surget A, Belzung C. Animal models of major depression: drawbacks and challenges. J Neural Transm. 2019; 126:1383-1408. doi: 10.1007/s00702-019-02084-y.

19. Million M, Tache Y, Anton P. Susceptibility of Lewis and Fischer rats to stress-induced worsening of TNB-colitis: protective role of brain CRF. Am J Physiol. 1999; 276(4): G1027-36. doi: 10.1152/ajpgi.1999.276.4.G1027.

20. Owashi T, Otsubo T, Oshima A, Nakagome K, Higuchi $\mathrm{T}$, Kamijima K. Longitudinal neuroendocrine changes assessed by dexamethasone/CRH and growth hormone releasing hormone tests in psychotic depression. Psychoneuroendocrinology. 2008;33(2):152-161.

21. Raglan GB, Schmidt LA, Schulkin J. The role of glucocorticoids and corticotropin-releasing hormone regulation on anxiety symptoms and response to treatment. Endocr Connect. 2017;6(2):R1-R7. doi: 10.1530/EC-160100 .

22. Herbert J. Cortisol and depression: three questions for psychiatry. Psychol Med. 2013;43(3):449-469.

23. Gallagher P, Young AH. Mifepristone (RU-486) treatment for depression and psychosis: a review of the therapeutic implications. Neuropsychiatr Dis Treat. 2006;2(1):33-42.

24. Numakawa $T$, Odaka $H$, Adachi N. Actions of brainderived neurotrophic factor and glucocorticoid stress in neurogenesis. Int J Mol Sci. 2017;18(11):2312. doi: 10.3390/ ijms18112312.

25. Gesmundo I, Villanova T, Gargantini E, Arvat E, Ghigo E, Granata R. The mineralocorticoid agonist fludrocortisone promotes survival and proliferation of adult hippocampal progenitors. Front Endocrinol (Lausanne). 2016;7:66. doi: 10.3389/fendo.2016.00066.

26. Savitz J, Lucki I, Drevets WC. 5-HT1A receptor function in major depressive disorder. Prog Neurobiol. 2009;88(11): 17-31. doi: 10.1016/j.pneurobio.2009.01.009.

27. Zhao Y, Ma R, Shen J, Su H, Xing D, Du L. A mouse model of depression induced by repeated corticosterone injections. Eur J Pharmacol. 2008;581(1-2):113-120. doi: 10.1016/j.ejphar.2007.12.005.

28. Malyarenko TV, Vishchuk OSM, Ivanchina NV, Kalinovsky AI, Popov RS, Kicha AA. Four new sulfated polar steroids from the far eastern starfish Leptasterias ochotensis: Structures and activities. Mar Drugs. 2015;13(7):4418-4435.

29. Zhen XH, Quan YC, Jiang HY, Wen ZS, Qu YL, Guan LP. Fucosterol, a sterol extracted from Sargassum fusiforme, shows antidepressant and anticonvulsant effects. Eur J Pharmacol. 2015;768:131-138. doi: 10.1016/j. ejphar.2015.10.041.

30. Tsang CK, Ina A, Goto T, Kamei Y. Sargachromenol, a novel nerve growth factor-potentiating substance isolated from Sargassum macrocarpum, promotes neurite outgrowth and survival via distinct signaling pathways in PC12D cells. Neuroscience. 2005;132(3):633-643.

31. Kapoor R, Peyear TA, Koeppe RE 2nd, Andersen OS. Antidepressants are modifiers of lipid bilayer properties. J Gen Physiol. 2019;151(3):342-356.

32. Ingólfsson HI, Thakur P, Herold KF, Hobart EA, Ramsey NB, Periole X, et al. Phytochemicals perturb membranes and promiscuously alter protein function. ACS Chem Biol. 2014;9(8):1788-1798. 